\title{
Cognitive Cybernetics vs. Captology
}

Zdenko Balaž*, Davor Predavec

Zagreb University of Applied Sciences, Electrical Engineering Department, Zagreb 10000, Croatia

\section{A R T I C L E I N F O}

\begin{tabular}{l} 
Article history: \\
Received: 29 September, 2017 \\
Accepted: 06 November, 2017 \\
Online: 20 November, 2017 \\
\hline Keywords: \\
Captology \\
Cognitive Cybernetics \\
Intelligent Systems \\
Expert Systems \\
Learning Mechanisms \\
Motivation
\end{tabular}

\section{Introduction}

This article extends the work originally presented at 40th International Convention on Information and Communication Technology, Electronics and Microelectronics (MIPRO), Opatija, Croatia, May 2017, [1-4]. The presented paper confirmed how human mind development is being contributed by the 'smart' creations of intelligent technologies as artificial intelligence (AI) products. Researches have been devoted to methodological directions and developing concrete tools for self-analysis and synthesis, simultaneously providing exhaustive theories about

*Corresponding Author: Zdenko Balaž, Našička street 59, 10110 Zagreb, Croatia, +385993111460 Email: zbalaz@tvz.hr

www.astesj.com

https://dx.doi.org/10.25046/aj020614 human nature being experienced as a 'new philosophy', but also as an 'anti-philosophy', defined on a new scientific course called cognitive cybernetics.

Cognitive cybernetics is the expansion of the 'classical' cybernetics, which includes scientific comprehensions of cognitive control and regulation of artificially-technical and socio-technical systems, biological organisms, organizations, processes, structures etc. The cognitive aspect of all evaluated systems elaborates and applies cognitive models, cognitive-functional and procedural system implementation, problem-solving based on natural methods by analogue cognitive computer techniques and lastly, the realization of system solutions and their organization in the context of management approaches and methodologies. This work is based 
on the cognitive development and implementation of ITK's (Ingenieurgesellschaft für Technische Kybernetik, Rülzheim, Germany) education modules in cooperation with National University of Vietnam, Hochschule Offenburg and Electrical Engineering Department at Zagreb University of Applied Sciences.

Cognitive Cybernetics recognize motivation as an internal state that excites, directs, and maintains the behavior of an individual. In education and training, motivation is especially important both for learning and for seeking the purpose and meaning. In academic activities or preferences, latter is described as meaningful and effort-worthy exertions, while tend to be realized and applied within importance of higher levels competences and skills. Those who are more motivated have a greater positive attitude on everything, and so on education; they persist longer in more difficult tasks, process information at a deeper level and excel in learning experiences. The classic distribution of motivation on intrinsic and extrinsic motivation in education is an incentive for activities which:

- represent the challenges of optimally assessed goals,

- can be controlled for goal achievement, which is emotionally fulfilling,

- establish the autonomy of action through the existence of feelings that can be controlled and have the effect on own development,

- encourage curiosity for the new, surprising experiences that increase the intrinsic motivation,

- include creativity and imagination where the motivation awareness is confirmed by imagination.

Approaches for defining motivation in education are:

- Behavioral approach in which understanding of motivation begins with a careful analysis of incentives and awards,

- Humanistic approach that emphasizes the understanding of the need for self-reliance through the stimulation of internal resources (sense of competence, self-esteem, and autonomy),

- The cognitivistic approach that accepts the fact peoples' activity and curiosity are inherent, and they seek information to solve relevant tasks.

An integrated approach for creation of education based on cognitive cybernetics foundation, considers:

- socio-cognitivistic focus on individual's behavior and potential interest for the impact on beliefs and expectations,

- the socio-cultural atmosphere created by participation in the community, in activities that maintain the identity of the community's interrelationships.

Therefore, motivation in the community is strengthened by the education to which it belongs and appreciates it. Specialist tutoring programs are the foundation for acquiring an expert status, where the very understanding of problem-solving is needed at that level, for which is necessary to gain the knowledge by understanding. Elementary forms of understanding are prescribed by the concept of objective mind or spirit, which guarantees the possibility of intersubjective communication at the basic level. 'Higher forms of understanding' occur when one internal difficulty or contradiction confronts with what is already known. It is then necessary to summon up and include the entire life structure, (establishing a relationship between life expression and its cognitive content), which can be found in its hermeneutical understanding, [5-8]. Research results show that understanding develops through information processing and modifies over a longer period. At a somewhat higher flexible cognitive level, it is possible to cognitively gain skills through which information is processed both intuitively and analytically. This knowledge, along with the persuasive context and information technology, closes the 'hermeneutic circle of artificial intelligence', Figure 1.

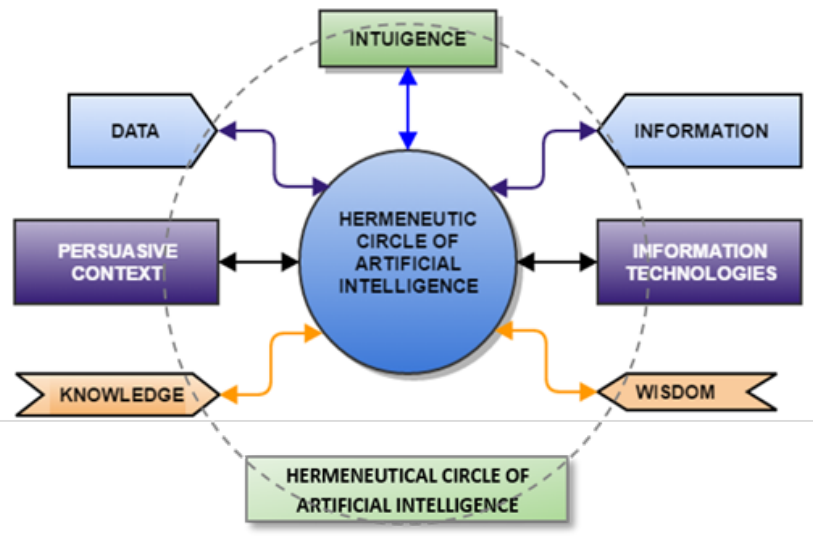

Figure 1 - Hermeneutical circle of artificial intelligence

\section{Cognitive cybernetics - the future of education}

Researches that deal with the captological components of intelligent and interactive technologies are confirmed by cognitive cybernetics through simulation examples of human thinking. Approaches to the study include analytical levels by evaluating the system almost in all technological branches and domains with the assumption of significant and dramatic advances in neuroscience, genomics, robotics, nanotechnology, computers and artificial intelligence with the help of other interdisciplinary studies, shown in Figure 2.

Studies and researches have further led to transhumanism extremes that advocates human body modification, including mental and psychological changes, all to control desires, mood and mental states. The everlasting fight against aging and illnesses is therefore not the only task of transhumanists, but also a try to improve the man at all levels, emphasizing simultaneous mental and physical advancements would be desirable.

If transhumanism associated with humanism is recognized as writing it as 'trans + humanism', then from the enlightened humanism comes the emphasis of a progress (its ability and desirability, not its inevitability), personal responsibility to create a better future and progress to a new society, but at the same time the awareness of accidents that can be caused by technology misuses in such society. For these reasons, it is necessary to differentiate the forms of meaning (i.e. primary and secondary), on which science assignments are based, and values that are recognized in the world, [9], addressed below in Figure 3.

Treatment by cognitive science has selected, among other things, certain factors of one's individual ability expectations to achieve desired goals and their value, respectively. 


\begin{tabular}{|l|}
\hline \multicolumn{1}{|c|}{ COGNITIVE SCIENCE } \\
\hline Study of the Mind \\
\hline $\begin{array}{l}\text { Structure of an interdisciplinary research: psychology, } \\
\text { psychiatry, neuroscience, linguistics, anthropology, computing, } \\
\text { biology \& physics }\end{array}$ \\
\hline \hline Evaluation approach through the system: \\
Symbolic system - claims that cognition can be explained using \\
symbolic operations through explicit mental (but not cerebral) \\
computational theories and models of the processes that are \\
analogue to the work of a digital computer. \\
Connectionistic (sub-symbolic) system - claims that cognition \\
can be modelled and explained only by using artificial neural \\
networks at the physical cerebral condition level. \\
Hybrid system - claims that cognition is best modelled while \\
connectionistic and symbolic systems are combined, and if \\
possible, with other computational methods. \\
Dynamic system - claims that cognition can be explained through \\
continual dynamic system wherein all elements are interconnected, \\
as a centrifugal regulator. \\
\hline \hline \multicolumn{1}{c|}{ The levels of analysis: } \\
- Implementation (physical) level: describes the physical \\
substrate from which the system consists (e.g. brain, \\
neurons, etc.). \\
Algorithmic (functional) level: describes how is information \\
processed in order to produce a bihevioral output. \\
Computational (behavioral) level: describes directly observable \\
output (or behaviour) of a system. \\
\hline
\end{tabular}

Figure 2 - Interdisciplinary study of the mind and intelligence through level analysis over the system

\section{FORMS OF MEANING}

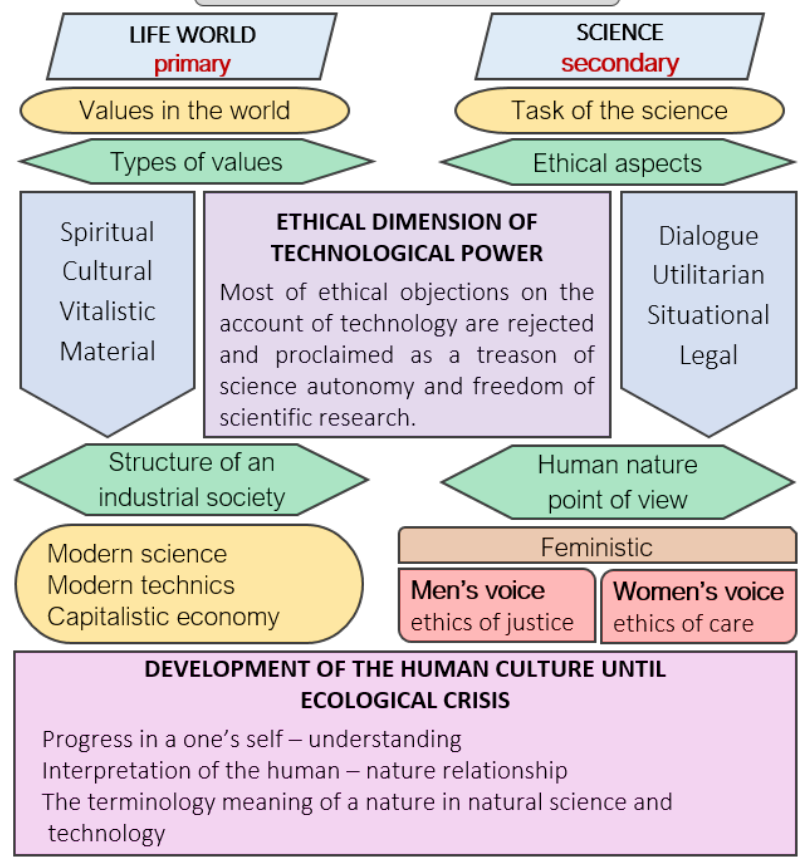

Figure 3 - Primary and secondary forms of meaning and ethical dimensions of technological power

Apart from this, it is accepted the fact that a man is a cognitive, reasonably-minded being, who accomplishes its own understanding at two levels. The first one is subjective level or the level of psychological participation, and the second is objective level or the level of intellectual participation. Hence, it is possible www.astesj.com to conclude that hermeneutics is a universal theory of understanding in which no confusion is present because hermeneutic understanding is neither interpretation nor explanation. In this way, a differentiation between the objective understanding of the meaning on one side and subjective understanding of motives and intentions on the other side can be made. Theoretically, it is possible to attain adequate learning processes from the book, without producing any external signs of acceptance and application of such learned matter. The effects of learning efficiency, whose outcome must have been understanding, depend on many factors such as physical and biological states, prior knowledge, daily oscillations in the brain chemistry, peptide hormone levels, and ultimately - the captology. Therefore, in understanding the recognition of its either elementary or higher forms for the purpose of education system, it is important to point out the most important motivational variables, namely:

- needs,

- beliefs,

- goals as outcomes to be achieved,

- internal interest,

- emotions.

These variables are linked and processed through natural analogue systems, confirming the new concept in cognitive cybernetics - 'Brainware', [10].

\subsection{Needs}

Although there are many theories, all rely on the most famous one - the Maslow's hierarchy of needs that differentiates the needs of a lower order or the needs of lack - survival, security, affiliation, and self-esteem, and the needs of higher levels or the growth needs - intellectual success, aesthetic assessment, and selfrealization. The latter needs can never be fully met, since when one desire is fulfilled, the other one immediately takes its place. Newer approaches to the motivation influenced by intelligent technologies focus on highlighting not only individual needs (a generated need to feel capability and competence), but also on interaction with the world, having the choice and feeling of controlling life, while at the same time on the challenge of connectedness through sustainability in the world. Such a theory, though seemingly presents the absurd paradigm because it reduces the basic human needs to autonomy, competence and connectivity, relies on the persuasion which is the second name for the captology present in cognitive cybernetics, Figure 4, [11].

\subsection{Beliefs}

Beliefs as a variable of cognitive cybernetic processing come down to the achievements of:

- knowledge,

- capabilities,

- causes and control,

- self - value. 


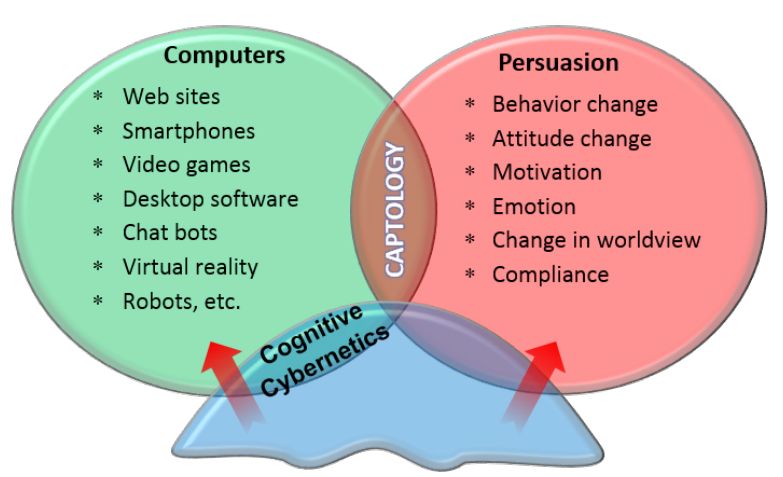

Figure 4 - The captology of cognitive cybernetics in computer persuasion, [11]

Knowledge beliefs are defined as beliefs about the structure, stability, and security of knowledge and as best ways of acquiring knowledge that influence learning strategies use.

Capability beliefs are one of the most powerful beliefs that affect motivation. There are two types of capability views: entity and incremental. The entity view refers to the belief that capability is a fixed characteristic and can not be changed. Although capabilities differ between individuals, their representation is potentially stable when acquired, but capability as a set of skills may change. By means of continuous work, learning and exercising, it is possible to increase one's knowledge and thus improve the capability.

Causes and control beliefs are based on attempt to understand the meaning of one's own and/or another peoples' behavior. This theory explains how individual explanations, justifications, and excuses about oneself and others affect motivation.

Self-value beliefs can be oriented to control or avoid failure. Orientation toward control seeks out the tendency of addressing value to achievement and the ability to set the attitude that achievement can be enhanced by targeting the goals. By mere control, one's own skills and abilities are being improved.
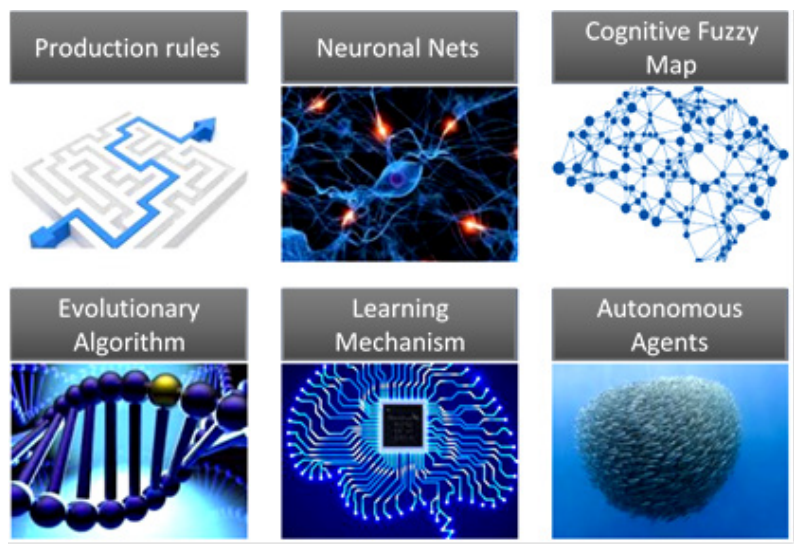

Figure 5 - Concept of cognitive solutions in environment, [11]

Orientation to avoid failure supports the entity's view of ability and sets further its goals related to performance. One can have a lack of strong ability sense and value separated from the performance, thus cognitive cybernetics serve as a simulation for technological and technical solutions (production rules, evolutionary algorithms, autonomous agents etc.), for the purpose of understanding and functioning of biological states (neural networks, learning mechanisms, cognitive fuzzy maps, etc.). In this way, mapped into education systems, strategies for avoiding failure are being worked out so they don't lead to a failure or to prevent the continuation of failure. Such strategies (shown in Figure 5) do not accept excuses or incapability, therefore the possibility to give up or accept a failure as a belief that problems arise due to low capabilities is not considered.

\subsection{Goals}

Goals are the outcomes or achievements to be attained and they enhance performance because they direct one's attention on the current tasks and divert from the distractors. Goals encourage devotion, for as the goal is as greater, such is the commitment. They increase perseverance, for when there is a clear goal, it is more difficult to give up. Furthermore, goals also encourage the development of new knowledge and strategies until they prove as successful ones.

Types of goals being set affect the extent of motivation that is needed to achieve them. Aims that are specific, moderately tough and likely to be achieved soon, often increase motivation and persistence. Just as goals, there are target orientations related to belief patterns about goals, also associated with achievements. Goals differ from the type of control, performing, avoiding the effort and social goals that need to be recognized for motivation.

The concept of cognitive solutions that today's civilizational environment treats as an agent systems by cognitive coverage of processes and programs, integrates human factors and machines (technologies) as inspirational cognitive goals, Figure 6.

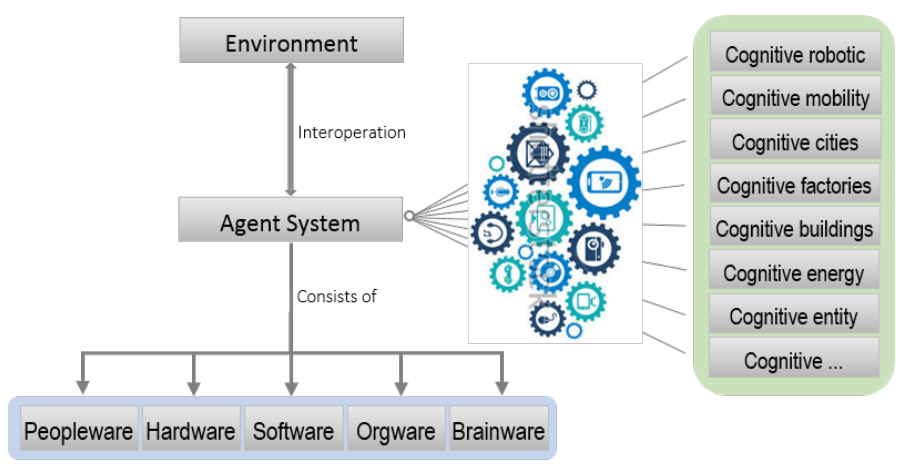

Figure 6 - Concept of environment cognitive solution set as cognitive goals, [11]

\subsection{Internal interest}

There are two kinds of interest: personal and situational. Personal interests relate to more persistent personal aspects, such as a long-term preference for the particular subject, while situational interests relate to short-term aspects of activity, such as a text or material that attract and retains attention. Interest in the education grows with a sense of competence, even if initially there was no interest in a certain activity. Cognitive industry, by 
its evolution, is an inexhaustible source of interests, and as such through modern civilization imposing itself as a leading variable. Within cognitive cybernetics processing and understanding, interest is related to entities (synonym for the subject, article, individual, being, form of life, body, creature, organism etc.), which in ontological terms is connected with different and independent existence plus applicability, and is profiled as a cognitive entity platforms, entity ecosystems, browsers, entities, services, service portals, interoperability servers, maintenance portals, integrated server, entity application as a tool, etc., Figure 7.

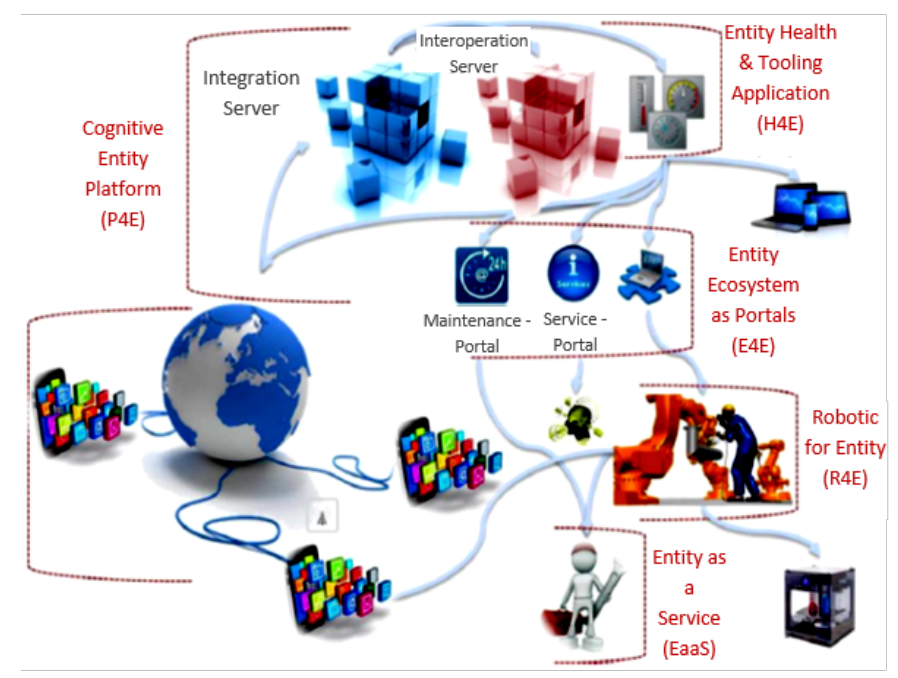

Figure 7 - Platforms of creating cognitive solutions as goal variables, [11]

\subsection{Emotions}

Emotions, especially pleasant ones, have very positive effects on ability beliefs (accepting an incremental view of ability), target orientation (associated with learning objectives), self-regulation, information processing (emotions are encoded with information), etc. Positive emotions encourage positive thoughts and memories, along with evaluation of education, hence such a positive effect is adequately treated for evaluation and performance of education based on the concepts of a system cognitive modelling.

In the beginning of education, emotions are very important, especially when it comes to the feelings of excitement, pleasure, fun, and curiosity, because these emotions can trigger a situational interest. It is only necessary to control them in order to prevent exaggerating effects which can lead to negative emotions, having a somewhat more complex relationship with motivation.

Additional stimulus to emotional motivation is the overoccupancy that refers to an intense form of intrinsic motivation in which an individual is in a state of profound insight, concentration and focus on the challenging activity. The experience of occupancy depends on autonomy. Intrinsic emotional motivation was often experienced in activities that were chosen willingly rather than imposed by others. Therefore, competence (skills and techniques) is so trained that it becomes automatic and is responsible for the optimal challenge (the optimal ratio of challenges and skills), creating a special emotional concentration that is not obscured with time and space.

\section{Cognitive cybernetics in mystical artificial intelligence implosion}

When artificial intelligence emerged in such terminology in the middle of the last century, it was the fastest growing scientific discipline. At the beginning of this century it started to be mystically missing in implosion, which can be attributed to a certain transformation. Development of artificial intelligence encompasses four periods of time, [10]:

- The period of enthusiasm and great expectations (1952 1969),

- The Age of Cognitive Reality (1966 - 1973),

- Knowledge-based Systems (1969-1979),

- The period of applicability (it begins in 1980s and continues as a process to date).

The fourth period is a process that goes through its five stages of transformation:

- The first stage is application of artificial intelligence in industry, from 1980s,

- The second stage is a transformation through neural networks, introduced in 1986,

- The third stage of transformation has placed artificial intelligence in the science, and is accepted since 1987,

- The fourth stage of transformation introduced superintelligent agents, in 1990s,

- The fifth stage of transformation is the mystical implosion of artificial intelligence that is still ongoing.

Mysticism in this matter is trying to point out that implosion is a way in which artificial intelligence disappeared within itself, and at the same time in some certain connectedness, cognitive cybernetics emerges. In that mysticism lies the impossibility of terminological discernment and a clear access to technological level called 'Industry 4.0', as well as transition and emergence of the new era of 'Evolution Industry - Industry X.X.', in which cognitive cybernetics has been already implemented. Therefore, regarding such a rapid pace, it can be concluded this already 'is' the future so widely present as a subject of discussions.

Today, this future is also called the 'Society 5.0', (germ. 'Gesellschaft 5.0'). The Idea of Society 5.0. was launched from the 'Fifth Scientific and Technological Fundamental Development Plans' in Japan by the end of 2015. The idea is to bring digitalization closer to all segments of society through the creation of a so-called 'super-smart society', whose core is the social impact of technology and which is focused on cognitive cyber-products. Production processes and production itself of these cyber-products are created by developed and self-regulated autonomous cycles, partly realized through the very products.

Toward adoption of the Society 5.0 strategy, on CeBIT meeting in Hannover, 25th of January, 2017, the Japanese Prime Minister (presented Japan as the partner country) and the German chancellor agreed about opinions that although the market 


\section{Z. Balaž et al. / Advances in Science, Technology and Engineering Systems Journal Vol. 2, No. 6, 107-118 (2017)}

prerequisites for further development brought by technology such as open borders, democratic values and a free trade, they stated: 'Millions of people do not know what to expect from the upcoming changes, and those who should change the policy and the digital sector in Europe which relies on cognitive cybernetics are often slow in key decisions'.

\subsection{Transformation approaches of cognitive cybernetics}

The mystical disappearance of artificial intelligence presented above and characterized as an implosion, further shows that the emergence of cognitive cybernetics can be studied through three approaches to that transformation, as addressed below.

\section{A. Anthropological approach}

The anthropological approach of artificial intelligence into cognitive cybernetics transformation relies on the study of a human species development (life and culture), which looks at the presence and future of the human race, and links:

- nature and culture,

- past and present,

- the uniqueness of the human race through diversity of its forms.

The relationship between nature (biology) and culture defines the development of human species through cortex specialization, which enables understanding, communication, and learning. Thusly created (learned) content is called culture. As a fundamental concept of anthropology, culture is a set of behaviors that people learn and share in a given period and in a chosen natural and social environment.

The relationship between past and present although in the evolutionary sense compared to other beings follows the same natural rules, enriches people with extraordinary ability to learn and pass on the knowledge from generation to generation. This approach has accelerated the cultural evolution which has become faster than the biological evolution. In this sense, profound differences are being outlined, not only in terms of anatomy and physiology, but also in terms of the very habits so different that the essential unity of the human race is not seen anymore, and therefore the potential for innovation is harder to be recognized.

The uniqueness of human race through diversity of its forms is a consequence of the lifestyle difference not only in different times and areas, but also within the same society due to regional specialties based on the economy and different living conditions as entities. Within the same area, differences exist in the way of certain communities' lifestyle, not only immigrants' ones, but also among the sexes, ethnic, age and class groups. Responses about purposefulness inquiries given from anthropology are used to understand, create and inspire cognitive cybernetics.

\section{B. Ontological approach}

Ontological approach to the concept of cognitive cybernetics relies on strictly traditional philosophical discipline as the central branch of metaphysics that studies the being, if it is a being, as such. Modern analytical ontology is, above all, the theory of general categories such as object, attribute, event, etc. Ontology is a study of nature of the things we find in our environment, around the world, and what relationships are among them. In addition, it is related to existence, objective property of things, space, time, causality, and opportunities that result from all of this. Since cybernetics within science explains the general principles of the process management, regulation, obtaining, storing, transforming and transmitting information, both in living beings and in technical systems, therefore as a scientific discipline explores a dynamic self-regulating and self-organizing systems, while through ontologic patterns also defines system properties. In this way, accessibility is recognized in environment and by means, changes as responses within. Activity as operation is directed towards achieving the goal through takeover of the initiative. Socialization that works together with other systems and people to achieve goals also helps others in achieving theirs. Furthermore, mobility opens the possibility of acting in any environment and lastly, a learning ability based on understanding human intelligence and communicating with machines ensures exceptional availability.

Ontological approach enables expansion and connection with boundary theory areas of a system, management, information, coding, logic, formal languages and grammar, games, mathematical algorithms and programming, and robotics, which include all four existing types of cybernetics:

- Theoretical or general cybernetics,

- Applied or applicable cybernetics,

- Technical / technological cybernetics,

- Economic cybernetics.

Their most important features are the features of the system:

- a great complexity,

- stochasticity and

- auto-regulation.

Recognizing these cybernetic characteristics and features enables ontological observation through its theoretical, technical and economic views.

Theoretical point of view represents the logical structure of hypotheses, knowledge, discoveries, scientific facts, theories and laws. It involves observing, collecting, measuring and rendering data, and lastly, data experimentation, for ensuring optimal conditions under which data, information and knowledge can be obtained. The economic or organizational standpoint provides rational technology intended for further research in all essential elements.

\section{Captological approach}

The captological approach to cognitive cybernetics includes the cognitive character of persuasive technologies and as a superior scientific field introduces expansion limes on ethical principles. This approach to cognitive cybernetics through its purposefulness in industrial ecology, an emerging scientific interdisciplinary field, unites its development by combining natural, technical and social sciences into a unique system from 
global to local level. Foundation of this concept is a cognitive captological integration based on analogy between intelligent technologies, processes in nature (biosphere) and processes in society (technosphere), Figure 8.

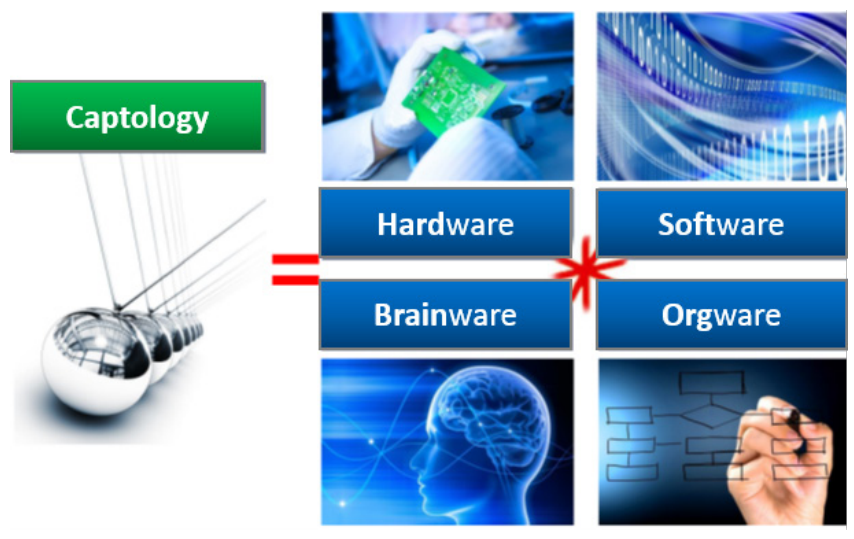

Figure 8 - Captology as a threat to innovation's access and openness

The biosphere, with its laws and principles, refers to coniferous life around the planet, summed up in earthly life as a whole in which all transformations take place. Technosphere is an artificial sphere of all kinds of technology around the planet (all technical and technological aids, creations and systems), with its own artificial time functions in which everything is immersed. Today, the ultimate development and application of intelligent technologies is experienced as a planetary intelligence system made by the Internet, mobile communications, applications and virtual structures of technological simulations. Cognitive cybernetics might enable the creation of awareness of innovations that will drive evolution of life on Earth only in a mental and spiritual direction, [12-15].

\subsection{The role of human factors in cognitive cybernetics}

Cognitive cybernetics has advanced to such a degree that it can do all the imaginable management and monitoring in a hardware sense. For its efficient application, education is needed to acquire special skills, knowledge and competences required for unerring behavior of decision-makers in approaches to accept innovations and consider scrupulosity. Herein come invaluable characteristics of the ability to use a 'common sense':

- Expressive abstraction and conceptual analysis for quick and successful problem solving in unexpected situations

- Unlimited flexibility.

Certain problems can be identified through persuasion perfidy in the context of treatment and understanding data and information. Research has confirmed that 'third-party tools for experiments on users from database software algorithms evaluate and rank all information accessed through the network - currently $95 \%$ for which an average educated user reaches!? Thus, it is not surprising fact that over 300 trials and about 200 signals are continually being run on a daily basis, watched and measured to help maintain 'freshness' and the speed of collection, securing, and transferring data. Although scarcely mentioned, but shows persuasion as useful, the captological arsenal is revealed as:

- Cognitive prejudices, (between more than 170 cognitive prejudices emphasize the "unwillingness of taking risk in time deficit', and which has been led by persuasive message),

- The weapon of persuasion (this is about persuasive techniques that rely on the 'principle of scarcity' and the 'theory of authority acceptance'),

- Productivity laziness (confirmed by the fact of human mind laziness and the tendency to skip or careless reading which, due to the persuasive guidance, results in unwanted consequences),

- Decision-making fatigue, (associated with the user exhaustion by persuasive over-offerings that encourage the use of lower resistance paths).

The brain capacity for learning is enormous and created for more demanding intellectual activities than the ones commonly included into. The human brain possesses two mutually independent systems of receiving and thinking. The leading one is in the left half of the brain and it analyses, writes, reads, talks and receives logically. The main center for feelings in the right half of the brain is more complete, emotional and associative, or better said - intuitive. Selected activities of the left and right hemispheres of the brain help to its learning by the pairs model (challenges and feedbacks).

The right side of the brain is used for intuitive handling of problems based on two components:

- Simple provisional rules that exploit the proviso to hit the most important information but ignore everything else, hence allowing a quick reaction,

- Predispositions of evolved brain abilities - skills acquired by genetics and learning to transform predisposition into the ability.

As the human mind develops regarding to inexhaustible desire to try and change, not just by wanting to always follow only 'reliable' answers, the question is whether the brain can be stimulated to develop when captologies is not new but uniform, deadening situations.

\subsection{Conducted trials}

In addition to aforementioned persuasive addictions, the results of 'tests/exercises' can be joined from originally elaborated materials of the course Intelligent systems, conducted at the Zagreb University of Applied Sciences, Electrical Department. It is basically about mechanisms and elements of conclusion through knowledge bases and databases of an expert system. Conclusion is gained by applying acquired knowledge about distributed artificial intelligence in correlation with human intelligence and social predisposition. The task is precisely described by instructions each student receives in the envelope, and before starting, teacher reads the instructions aloud before all 
students at the initial location of the exercise. The task is shared to two groups of students who, after receiving the instructions, go at two different locations. Students have drawn attention for having the opportunity to cooperate with each other, which is the goal of exercise, at last. There are five simple questions needed to be answered in manner that all students participate and create common, identical answers. The guideline text is divided into three parts (task description, approach to solving and solution guidelines). Conducting this exercise within four educational periods in three academic years, 148 students participated, and the task was successfully solved not even once.

The reason why such a simple task has not yet been solved lies in the hyper-offer of data (information). Students are mostly taught that use of information technology encourages rapid data inspection. By doing such, reading of the task is reduced to mere browsing and is very superficial, which makes easier overlook of the solving approach. Too much data drives away from deeper and more permanent entry into any single argument, fact or idea. An overwhelming number of information and characters nullify themselves. Students are apt to access the search by going to links (connections) irrelevant to problem solving, but seemingly interesting information is the very beginning of current potential termination of available concentration. This outwardly produces impatience, a lack of attention and the absence of co-operation, respectively. As in reviews and surveys of a vast data, users are prompted to quickly come and go; the same effect was achieved through the lumped text of this task. In this journey of a rapid collection and data transfer, the cognitive efficiency is lost, unfortunately. A lot of confusing information and attentionshifting parameters fragment, hinder and distort the flow of thoughts that end up as distraction. The use of mind is under influence of intelligent technology and therefore under the pressure. Part of the human mind in charge for critical thinking, analysis of reality and which should be used daily as a way of thinking in solving problems, but also in social interactions when it serves to connect with the outside world, doesn't come to the expression in this task, and there was no created understanding mind is lost in captology for it does not follow the evaluation sequence.

\section{A. An example of understanding when meeting other people}

As an example of understanding, a study was conducted related to learning of understanding when meeting other people, already discovered by William Outhwaite, who had been looking at such situations through four categories:

1. The category of physical facts that can be noticed (how people look and what is the consequence of that). These are understandable phenomena in relevant sense, when being seen as a sign of something not physical from the past or something related to the mental state.

2. The category of mind states in others that can be identified now or can be inferred based on the previous comprehension.
3. The category of others' actions (by noticing what others do and what they consider to be doing) is described with three sub-categories:

a) Recognizing an action by approaching from distance,

b) Accepting of what is being said about on the same elemental level,

c) Complex judgment of the real importance of what is being done or what is thought to be said;

4. The category of questions why certain things are being done, and what motivates people to do them.

Latter categories try to establish a difference (especially between the states of third and fourth category), or the differences between motives and the 'hermeneutic understanding'. Psychological understanding of the human mind mental states can be observed based on three conclusions about peoples' motives and their intentions, which are the following: a) visible signs, b) explicit statements, and c) knowledge of the 'situational facts', confirmed by the psychology of the situation that has been discussed since Aristotle, Figure 9. From the aforementioned examples a complexity of the understanding comprehension can be seen, which is theoretically evaluated; and people have a social process of meeting embedded in a sub-conscious algorithm operable in real-time.

\section{B. An example of learning understanding while reading aloud}

To confirm the conducted research, it is useful to consider the acquisition of understanding on research example of literacy development. Therein, it comes to conclusion that the central process of learning by reading is understanding the text and active search of meaning and purpose, as established by G. J. Whitehurst and C. J. Lonigan. The reading process or understanding what was read comes down to understanding of coding and decoding, like digital data transmission. This also presents the concept of an expert system functioning, which was followed herein for explanation and elaboration.

- Rethorical
- Situational relationships
- Shared with others
- Transformation and
development
- Mutual action
- Concreteness of time
Theory and practice perspective

Figure 9 - Analysis of the situation psychology as a situational structure of significance 


\section{Z. Balaž et al. / Advances in Science, Technology and Engineering Systems Journal Vol. 2, No. 6, 107-118 (2017)}

Researches on reading effects has set the groundwork for reading mechanisms evaluation, which are:

- a comparison,

- a recall from the memory,

- linking what is seen or heard, (or heard before),

- identifying essential data and rejection of redundant ones.

On these grounds, data processing while reading developed by R. J. Marzano and D. E. Paynter happens simultaneously with five concurrent processes, known as a 'Model of 5 babushkas', Figure 10, which comprises:

- Understanding the purpose of reading,

- Estimating the compliance of read data with the purpose,

- The meaning of the smallest thinking units (claims),

- Identifying the meaning of words,

- Recognizing the meaning of a read wholeness.

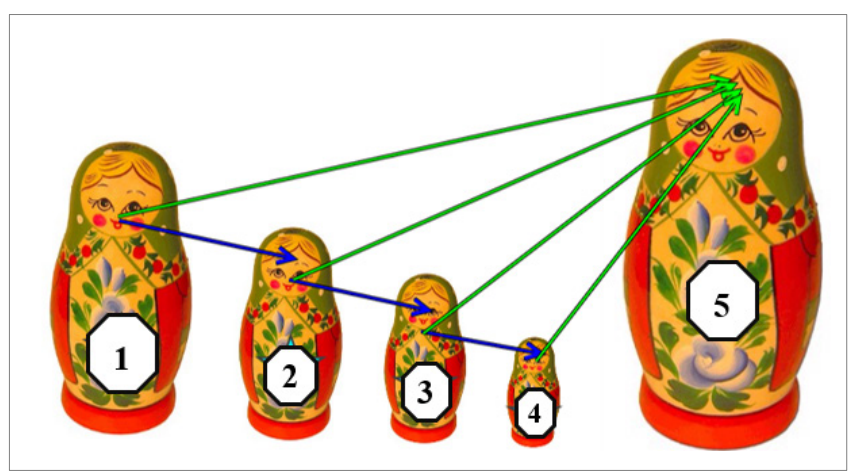

Figure 10 - Data processing while reading, (the model of 5 babushkas)

Reading, listening, watching and pronouncing are the ways of learning and each has a different contribution to learned matter. In accordance with learning mode, the left and right hemisphere along with emotional center of the brain are activated. Understanding the reading comprehension (reading aloud) is an understanding strategy that along with understanding, implies the voice sensitivity and motivation development. The abovementioned examples, especially data processing while reading, is an important foundation for analyzing different types of reading, such as:

- mature reading,

- reading a linear text - a printed book,

- reading a linear text - e-book,

- reading by text search - a computer,

- reading hypertext - a computer,

and where reading should be distinguished from a mere search, under the influence of captology and turned into an addictive need, because it maintains a worthless dominance over digital information flow. The imposed 'Internet ethics' through different kinds of media results in persuasive addiction manifested by:

- encouraging and treating a 'thirst' for small and short-term information slots,
- curious dependence on a continuous data stream updated in the real-time; an 'updated status' which lost its purpose slightly after a few moments of release, and

- the desire to speed up the flow of information.

Aforementioned manifestations hold not any contribution to storage of learned, because nothing has been learned. Moreover, a disturbance has occurred, and no recognized brain cell nor emotional center has been activated, which today can be safely confirmed by psychometric investigations for more serious (i.e. legislative) use, still deliberately delayed, while minor trials so needed have not yet been clearly recognized and are ongoing through new researches.

\section{An example of a thought material storage}

In support of the researches conducted, there is also an example of storing thought material in the memory, which requires a careful and balanced information flow. An example can be visualized for the practical acceptance. It is easily possible by photography, Figure 11, to identify a chair (or chairs) that represents a thought material which can be carefully and permanently stored in a visualized mental space.

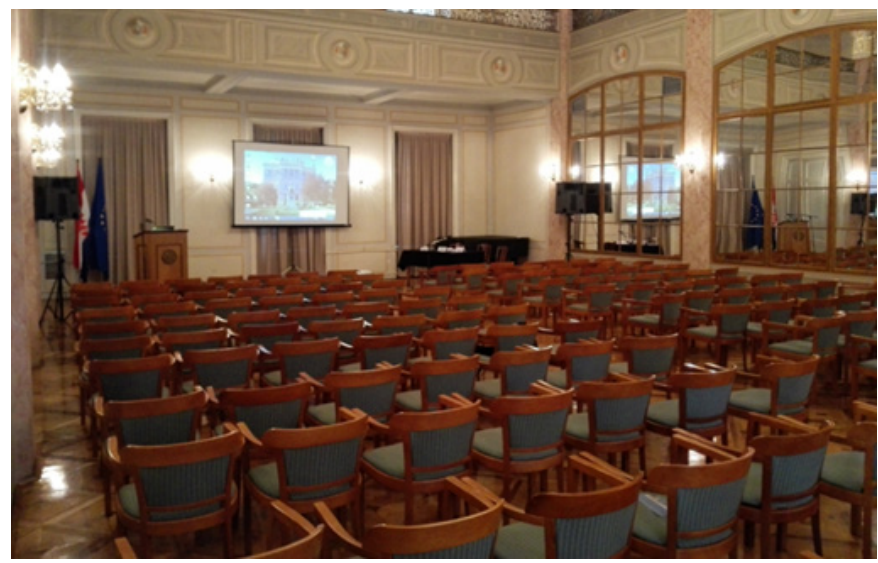

Figure 11 - The HAZU ${ }^{1}$ revival hall, Opatička 18, Zagreb - an example with a careful and balanced storage of thought material

An example of a mess explains a fragmented, disturbed, and a ruined flow of thoughts that end up as a distraction. Hardly anyone will be able from the photos, (Figure 12 and Figure 13), to recognize the thought material at the glance, the 'seat', which should be stored in the permanent memory. Careful and balanced storing of thought material in a chaos is impossible, because from a visualized matter a particular psycho-culture is participated, lately projected in all spheres of life.

The term 'psycho-culture' comes from the culture (lat. colere cultivate, nourish, cultos - processing, nourishing, cultivating), which represents an integrated system of attitudes, beliefs and behavior patterns characteristic for the members of society and which are not a result of biological heritage, but a social product created, transmitted and maintained through communication and 


\section{Z. Balaž et al. / Advances in Science, Technology and Engineering Systems Journal Vol. 2, No. 6, 107-118 (2017)}

learning. The function and meaning of the culture are facilitation, extension and development of the human society.

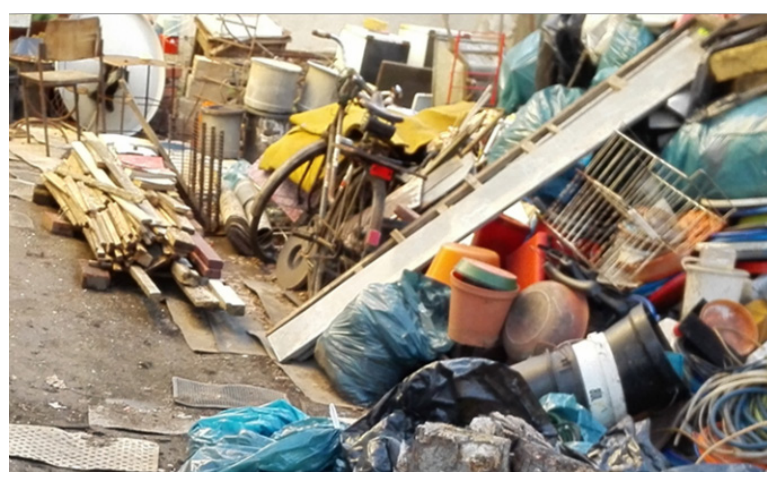

Figure 12 - The courtyard of the house, Trešnjevka in Zagreb - an example of thought material storing represented by mess and chaos

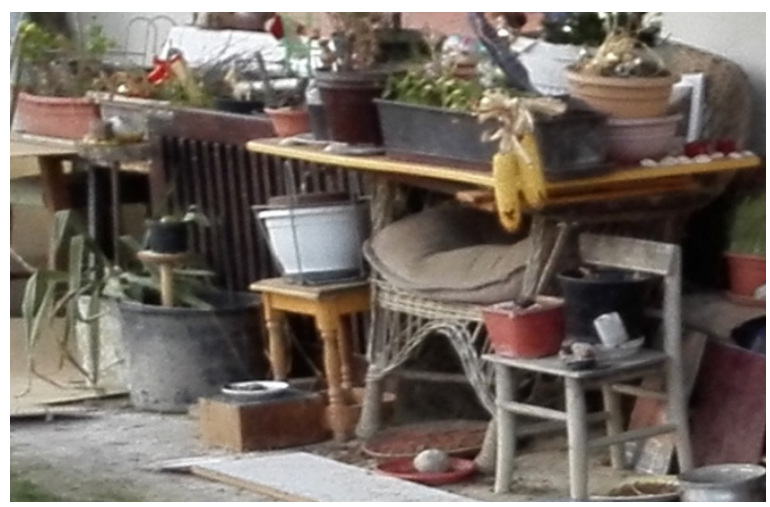

Figure 13 - The environment of the building, Hrgovići settlement, Trešnjevka in Zagreb - an example of thought material storing represented by mess and chaos

Culture arises from the peoples' need to master the nature and to be free from animalistic life, so that man does not cultivate only external nature but also his own, thus achieving the process of humanization. Under various influences and so under the influence of intelligent technologies, culture is subjective to collective programming of the mind by which members of one community differ from others. Psycho-culture associated with Cicero's cultivation of the soul from ancient times (lat. cultura anima), I. Kant evolves and develops it through his 'categorical imperative' as a noble trait, but also recognizes the formation of a collective mentality in society achieved by a dominant ideology and which directs social and political processes. Each person has its own ideology, a system of values and life orientations that direct through life and determine the behavior influenced by intelligent technologies and intuigence (intuition + intelligence), [16-23]. Socio-cultural neuroscience provides better and better insights into complex interactions between socio-cultural and neuronal structures and processes, and thus within biological mechanisms that underpin socio-cultural phenomena and human behavior including all components of Kierkegaard's existentialism.

For these reasons it is useful to point out that the structure of neural network, part of the big brain cortex, represents the biological basis of our mental abilities. In adulthood, new knowledge and skills are easily adopted without changing the structure of the neural network. On the other side, educational, psychological, social and emotional environments during such development change the very structure of the neural network, especially in the brain parts crucial to adopt the most complex brain functions. This includes the affective modulation of emotional expression, the conceptualization of one's own mind, mentalization, cognitive flexibility and a work memory.

\section{Continuation of research}

The continuation of researches presented in the paper is based on the prepared teaching material, [24-28]. In the new education period part of the Intelligent Systems program is transformed into a new area, [29-34]. This new area will be presented at the 1st International Conference on Intelligent Human Systems Integration: Integrating People and Intelligent Systems (iHSI 2018), which will be held at the JW Marriott Marquis in Dubai, United Arab Emirates, January 7-9th, 2018.

Authors in their work have come up with recognizing:

I. Human Intelligence Systems, (HIS) - at the very beginning of the 1980s, researches in the field of artificial intelligence was focused on systems associated with human intelligence. Their goal was to incorporate the principles of human intelligence into intelligent platforms for data processing through artificial intelligent systems, which in turn resulted and actively contributed to the industry development and advancement of society, such as:

a) advanced development and use of mechanical systems and devices in industrial production as intelligent autonomous robots,

b) the introduction of humanoids into the social and palliative spheres of life.

II. Intelligent Human Systems, (IHS) - researches continued in the 1990s, conducted on already developed intelligent systems foundation with the intent of implementation in education, had included among others:

a) developing and upgrading intelligent interactive technologies for use in systems with algorithms involving the principles of human thinking,

b) scientific analysis of social activities and human intelligence through mathematical modelling, scientific brain research and cognitive sciences in general.

Such intelligent systems contain the knowledge of certain domains with sophisticated decision-making processes and the ability to explain their behavior. This feature shows the most important aspect of such systems - their ability to effectively interact with people in social environment, teaching, and assisting in availability and complex data manipulation. Furthermore, their use has resulted as a significant impact on human resources with the effect of increased demand for education, [35-40]. Knowledge (when considering Human Intelligence Systems / Intelligent 


\section{Z. Balaž et al. / Advances in Science, Technology and Engineering Systems Journal Vol. 2, No. 6, 107-118 (2017)}

Human Systems) on the moral plane is designed to achieve what is achieved physiologically by asking the following questions:

1. How does consciousness, starting from the physical plane, finally reach the moral one?

2. How is physical balance a first step towards moral balance?

3. How is every controlled act the path towards improvement?

4. How are the rules of control also the rules of training?

5. How there is no discussion without calmness?

6. How does raising a will as a freedom and reasonable energy give man the freedom, right and task to choose between good and evil?

Although there are some suggestions today, it is more probable that in the near future answers to above questions need to be considered taking into account the parameters listed in Table $1,[41-45]$.

Table 1 - Parameters of the future considerations and justifications of Human Intelligence Systems / Intelligent Human Systems areas

\begin{tabular}{|c|c|c|}
\hline Genetic neo-construction & Transhumanism & Ultra-Intelligence \\
\hline \multirow[t]{2}{*}{ Genetic Technology } & Singularity & Super-Intelligence \\
\hline & Extropy & \\
\hline Biotechnics & Cyberpunk & $\begin{array}{l}\text { Historical } \\
\text { apokatastasis }\end{array}$ \\
\hline \multicolumn{3}{|l|}{ Bionics } \\
\hline Bioethics & Posthumanism & $\begin{array}{l}\text { Human-biological } \\
\text { planning }\end{array}$ \\
\hline Biopolitics & $\begin{array}{l}\text { The epoch of } \\
\text { hypermodern }\end{array}$ & $\begin{array}{l}\text { Spiritual } \\
\text { programming }\end{array}$ \\
\hline Bioconservatism & Nanotechnology & \\
\hline
\end{tabular}

\section{Conclusion}

Education for acquiring knowledge, skills and competencies will experience drastic changes in the near future because it will have to rely on cognitive cybernetics. In this paper, the results of research are presented as elaborated concepts of internationally recognized ITK institutions that launch new education programs with their partners. The Electrotechnical Department of Zagreb University of Applied Sciences is one of the partners since proven by its approach to educational standards formation and study programs alignment in polytechnic areas with the needs (existing and future) of the labor market, all in the context of globalization and technological development. Regarding to changes of higher education environment and the needs of labor market, it is necessary, as soon as possible, to harmonize them with the principles of cognitive cybernetics. This alignment must necessarily improve latter with introduction of new cognitive education modules because such activity of educational content should be a research for which human factors are at the same level of perfection and reliability as the available cognitive cybertechnology.

When information processing, problem-solving and decisionmaking are compared with expert system that contains human cognition and mental potential, it is possible to pull a parallel with intuition and intelligence.
The knowledge base is 'cognitively' dependent, associated with symbolic representation, and is identical to intelligence. Applying databases and knowledge bases, it would be useful to subject it to conclusion mechanism. This in biological sense of identifying with the human brain functioning (the way of thinking) suggests that purposeful use of intuition and intelligence require some sort of a skilled strategy - the intuigence, which has been confirmed by outputs of detailed researches carried out from 2008 to date, and which are presented in this paper.

When the education, psychological, social and emotional environment are linked to the presence and intimacy of intelligent systems and interactive technologies, the hypothesis of their multiple influences is confirmed; in a positive sense - through the knowledge of raising the level of integrated human mind development, and the negative one - the influence on people through neuropsychiatric disorders development. Biomedical and sociologically important concept is one of the main subjects of continuous discussion between advocates of selective theory against advocates of constructive theory of mental processing. Nowadays, the question about how to use the mind and intelligent technologies seems to be the same one. As one part of the human mind is in charge for critical thinking and reality analysis, it is used for problem solving but also in social interactions when it serves to connect with outside world. The second part of the mind is used for imagination and can only be triggered when the analytical opinion is excluded. The notion that imagination and analytical thinking are not treated as two opposing forms of thinking, but as two kinds of opinions with different functions, is the result of intelligent technologies impacts, for which human intelligence should set some directions and advices. For these reasons the question is set: does between cognitive cybernetics and captology exist a cooperation or the conflict?

\section{References}

[1] Balaž, Z., Predavec, D., "The Captology of Intelligent Systems" in 40th International Convention on Information and Communication Technology, Electronics and Microelectronics (MIPRO), Opatija, Croatia, May 2017. http://dblp.org/db/conf/mipro/mipro2017

[2] Balaž Z., Meštrović K., "Learning and teaching from Artificial Intelligence", (article in Croatian with an abstract in English), Zagreb University of Applied Sciences; Polytechnic \& Design, Vol. 2, No 1, pp 9-14; ISSN 18491995; Zagreb, 2014. http://polytechnicanddesign.tvz.hr/?page_id=363

[3] Balaž Z., Predavec, D., "The Brain lost in the space of persuasive noplacelessness", (article in Croatian), Public lecture and workshop conducted on 16th Brain week in Croatia, at Electrical department of Zagreb University of Applied Sciences, specialist graduate study, Zagreb, Croatia, $15^{\text {th }}$ of May 2017. https://www.bib.irb.hr/867247

[4] Predavec D., "The Captology of Intelligent Systems", Master's Thesis, Zagreb University of Applied Sciences, 2017.

[5] Afrić, V., "Theoretical basics of hermeneutics", (article in Croatian language), Sociological review, Vol XIV, No. 3-4, UDK 167.7:316, pp. 191 200, 1984. https://hrcak.srce.hr/155800

[6] Heidegger, M., "Ontology (Hermeneutics and Factuality)", BröckerOltmanns; Frankfurt a. M., 1988; Introduction to philosophical hermeneutics, Darmstadt http://www.iupress.indiana.edu/product_info.php?products_id=84761 
[7] Wilber K., A Theory of Everything: An Integral Vision for Business, Politics, Science and Spirituality, SHAMBHALA, Boston, 2001.

[8] Lachmann R., Phantasia Memoria Rhetorica, (book in Croatian) Translated by Davor Beganović, Press: Matica Hrvatska, ISBN 953-150-150-560-8; Zagreb, 2002.

[9] Balaž, Z., "Cognitive Cybernetics - a Future Society 5.0", the paper prepared for International Symposium P\&P, Zagreb, Croatia, October 2017.

[10] Haun, M., "Cognitive Computing - Steigerung des systemischen Intelligenzprofils", (article in German) ISBN 8-3-662-52951-5, DOI 10.1007/978-3-662-52952-2, Springer - Verlag Berlin, Heidelberg, 2014.

[11] Balaž, Z., Haun, M., "Cognitive Cybernetics - a future that is started" in 34th International Symposium on New Technologies, SOLARIS Hotel Niko, Šibenik, Croatia, 15th -16th May, 2017. https://www.bib.irb.hr/898570

[12] Teilhard de Chardin, J. M. P., L'Energie Humaine, (book in French), Editions du Seuil, Paris, 1962.

[13] Carr, N., The Glass Cage: How Our Computers Are Changing Us, (book in Croatian), Jesenski i Turk, Translated by Ognjen Strpić, Publisher: Znanje d.o.o..; Biblioteka „,42“; Zagreb, November 2016.

[14] Detlev v. U., Psychologie und Welt, (book in German) Verlag W. Kohlhammer, Stuttgart, Berlin; Koeln, Meinz, 1972.

[15] Gardner H., Kornhaber M., Wake W., Intelligence: Multiple Perspectives, Hercourt Brace College Publishers, Fort Worth, Philadelphia, San Diego, New York, Orlando, Austin, San Antonio, Toronto, Montreal, London, Sydney, Tokyo, 1996.

[16] Balaž, Z., The Intuigence and Captological Traps of Artificial Intelligence, manuscript of the book at a review process, Zagreb, November 2016.

[17] Sternberg R. J., Beyond IQ: A Triarchic Theory of Human Intelligence, Cambridge University Press, Cambridge, 1985.

[18] Sternberg R. J., The Triarchic Mind: A New Theory of Human Intelligence, Viking, New York, 1992.

[19] Anderson M., Intelligence and Development: A Cognitive Theory, Blackwell, Oxford, 1988.

[20] Figal G., Der Sinn des Verstehens, Beiträge zur hermeneutischen Philosophie, (book in German) Philipp Reclam jun., Studgart, 1996.

[21] Adorno T. W., Ästetische Theorie, (book in German) R. Tiedemann, Gesammelte Schriften, Frankfurt. M., 1970. - 1973.

[22] Gadamer H. G., Wort und Bild - So Wahr, So Sein, (book in German), Gesammelte Werke, Tübingen, 1993.

[23] Gadamer H. G., The Legacy of Europe; MH, Edition: PARNAS, Press: Targa, Zagreb, 1997.

[24] Balaž Z., Meštrović K., Haun M., Cognitive Cybernetics - Propaedeutic of Polytechnic, the book manuscript on review, prepared issue of teaching material for Manualia Polytechnici Studiorum Zagrabiensis, Zagreb University of Applied Sciences, November 2017.

[25] Balaž Z., Predavec D., "Integration of Cognitive Cybernetics into Intelligent Human Systems?", scientific article prepared for the 1st International Conference on Intelligent Human System Integration, Dubai, 7th -9 th of January 2018.

[26] Balaž Z., "Implemented research study", course: Artificial Intelligence Expert Systems, Electrical engineering department, Zagreb University of Applied Sciences, Specialist graduate study, $3^{\text {rd }}$ semester, September December 2013.; and course Intelligent Systems, $2^{\text {nd }}$ semester, September 2015. - December 2016.

[27] Balaž, Z., "Intuigence and captology of Intelligent technologies - challenges and fears", (article in Croatian), sent on Polytechnic \& Design journal, Zagreb University of Applied Sciences, October 2016.
[28] Parmy, O., "Jawbone guinea pig economy”, FORBES, Vol XIV, No 3-4, UDK 167.7:316, pp. 63-68, III. 2015.

[29] Faucault, M., "The Courage of Truth", (article in Croatian) lectures from Collège de France, (1983.-1984.), ISBN 978-953-7715-61-8, translated from French: Zlatko Wurzberg, Standorf \& Mizanotrop, Zagreb, 2015.

[30] Hoesle, V., "Filozofija ekološke krize", (article in Croatian) Moscow lectures, Publisher: Matica Hrvatska, Editor: Jelena Hekman, Press: Targa, ISBN 978-953-150-051-7, Zagreb, 1996.

[31] Grondin, J.: Sources of Hermeneutics, (book in Croatian) Publisher: Matica Hrvatska, Editor: Jelena Hekman, Press: Targa, ISBN 953-150-512-8, Zagreb, 1999.

[32] Jsselsteijn, W.I., Kort, Y., Midden, C., Eggen, B., Hoven, E., Persuasive Technology, ISSN 0302-9743, ISBN 3-540-34291-5, Springer - Verlag Berlin Heidelberg, LNCS 3962, 2006.

[33] Matulić, T., Metamorphosis of culture, Tertium mullenium, ISBN 97895324-1161-14, CIP 686343, Zagreb, 2009.

[34] Bubner, R., Izvornik, (book in Croatian) Aestetische Erfahrung, Suhrkamp Verlag, Frankfurt am Main, 1989. Translation: Estetsko iskustvo, Tihomir Engler, MH, Editor: Jelena Hekman, Biblioteka PARNAS, Press: Targa, ISBN 978-953-150-076-0, Zagreb, 1997.

[35] Carr, N., The Shallows: What the Internet Is Doing to Our Brains, (book in Croatian) Publisher: Jesenski i Turk, Translation: Ognjen Strpić, Zagreb, 2011.

[36] Kahneman, D., Thinking, Fast and Slow, (book in Croatian), Translation: Zvonko Pavić, ISBN 978-953-14-1483-8, CIP 857332, Publisher: Mozaik knjiga, Zagreb, 2013.

[37] Heisenberg, K., W., Physics and Philosophy, (book in Croatian), Translation: Stipe Kutleša, Kruzak, Press: S. Brusina - Donja Lomnica, ISBN 95396477-3-8, Zagreb, 1997.

[38] Voltaire, Treatise on Tolerance, (book in Croatian), Translation: Bosiljka Brlečić, MH, Editor: Jelena Hekman, Biblioteka PARNAS, Press: Targa, ISBN 953-150-082-7, Zagreb, 1997.

[39] Rohr, R., The Naked Now: Learning to See as the Mystics See, (book in Croatian), Edition: Synopsis, Zagreb - Sarajevo, 2016

[40] Petanjek, Z., "Sinaptički izazovi u djetinjstvu i adolescenciji: Izazovi i smjerovi suvremenog istraživanja mozga", (lecture in Croatian), HAZU: Symposium on Research and Brain Diseases, Zagreb, $16^{\text {th }}$ March, 2016. http://www.hiim.unizg.hr/index.php/24-naslovnica/334-simpozij-hazu2016-baw

[41] Jakovljević, M., "Mozak, duša i kultura u zdravlju i bolesti: Izazovi pred psihijatrijom 21. stoljeća", HAZU: Symposium on Research and Brain Diseases, Zagreb, $16^{\text {th }}$ March, 2016.

http://www.hiim.unizg.hr/index.php/24-naslovnica/334-simpozij-hazu2016-baw

[42] Goleman, D., Emotional Intelligence, (book in Croatian), Translation: Damir Biličić, Editor: Ivanka Borovac,, Publisher: Mozaik knjiga, $2^{\text {nd }}$ edition, available online, Zagreb 1997.

[43] Hood M. B., SuperSense: Why We Believe in the Unbelievable, (book in Croatian), Translation: Marko Maras, ISBN 978-953-303-175-0, Publisher: Ljevak, 2010.

[44] Paić, Ž., Posthuman Condition: The End of Human and Odds of Other History, (book in Croatian), Publisher: Litteris, ISBN 978-953-7250-41-6, Zagreb, October 2011.

[45] Paić, Ž., The Spheres of Existence: Three Studies on Kierkegaard, (book in Croatian), Publisher: Matica Hrvatska, ISBN 978-953-341-081-4, Zagreb, April 2017. 